\title{
Hydrogen bonds promote site-selective phenol functionalization enabled by $\mathrm{Cl}^{-}$anion
}

Yaya Wang ${ }^{\dagger \#}$, Kairui Zhang ${ }^{\dagger \#}$, Ruyi $\mathrm{Li}^{\dagger \#}$, Heng Luo ${ }^{\dagger}$, Zhu-Jun $\mathrm{Shi}^{\dagger}$ Xiaochen $\mathrm{Wang}^{\dagger}$ and Qian

$$
\text { Peng }^{\dagger}, *
$$

${ }^{\dagger}$ State Key Laboratory of Elemento-Organic Chemistry, Tianjin Key Laboratory of Biosensing and Molecular Recognition and Frontiers Science Center for New Organic Matter, College of Chemistry, Nankai University, Tianjin 300071, China. E-mail: qpeng@nankai.edu.cn

\# These authors contributed equally: Yaya Wang, Kairui Zhang and Ruyi Li

Dedicated to the 60th anniversary of Institute of Elemento-Organic Chemistry (Nankai University)

\section{Abstract:}

Most of studies for hydrogen bonds focus on the static model especially between two polar atoms. In contrast, introducing the third polar atom may emerge the competitive hydrogen bonds, which would represent a distinct perspective to perturb the catalytic chemical transformation. Herein, we report quantum mechanics calculations and quasi-classical direct dynamics simulations that demonstrate a triangle form of proton accepters enabled by $\mathrm{Cl}^{-}$anion can afford diverse hydrogen bonds, which control the reactivity and selectivity of $\mathrm{Rh}$ catalyzed phenol functionalization. A redox mechanism for carbene insertions with notable ligand effect was discovered and supported by both calculations and the experimental kinetic isotopic effect. The quaternary ammonium additive can stabilize key oxonium ylide intermediates with $\mathrm{O}-\mathrm{H}$...Cl hydrogen bonds that inhibit the common $\mathrm{O}-\mathrm{H}$ insertion and promote the carbene $\mathrm{C}-\mathrm{H}$ insertion product. The dynamic hydrogen bonds coupling with Rh complex dissociation may result in an intermediate shuttle of oxonium ylides, which unify the site-selective of the direct phenol functionalization.

TOC

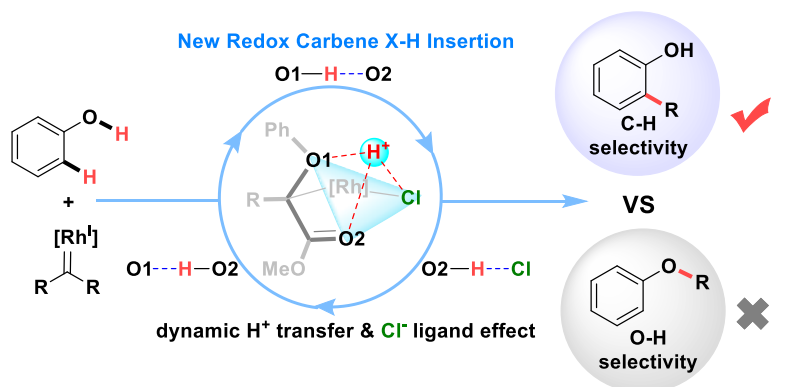




\section{Introduction}

Hydrogen bonds play critical roles in many biological macromolecules and organic reactions, and these non-covalent interactions can stabilize molecule structures or even the secondary structures (e.g. proteins) with favorable thermodynamic energies around 2-10 kcal/mol in water. ${ }^{1-}$ ${ }^{5}$ Besides the hydrogen bond formed between two polar atoms, it involving the third hydrogen accepter $\mathrm{Z}$ might interrupt the original $\mathrm{X}-\mathrm{H}$...Y interaction that competitively generates diverse hydrogen bonds through proton transfer as shown in Scheme $1 \mathrm{a}^{5}$ To the best of our knowledge, the triangle form of proton accepters mediated by the proton might control catalytic pathway that remain elusive (e.g. enzyme catalyst ${ }^{6}$ ). As potential carriers for hydrogen bonds, oxonium ylides provide intramolecular charge balance potentially involving hydrogen bonds, which set the stage for the investigation of new transformations and mechanisms. ${ }^{7-10}$ For example, oxonium ylide intermediates with static hydrogen bonds are likely responsible for the metal carbenoid $\mathrm{O}-\mathrm{H}$ insertion, reported by Yu's ${ }^{11}$ and Fang's ${ }^{12}$ group through DFT calculations.

Scheme 1. Dynamic hydrogen bonds and oxonium ylides for site-selectivity.

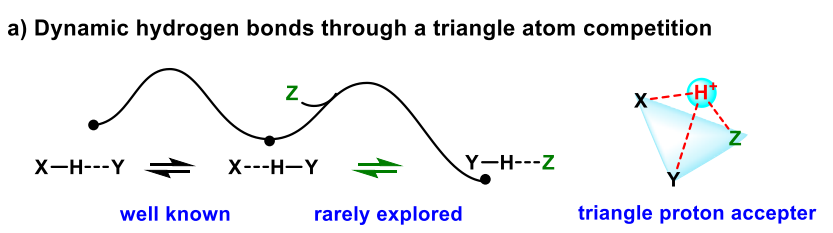

b) Experiments on selective carbene insertion of unprotected phenols. ${ }^{21}$

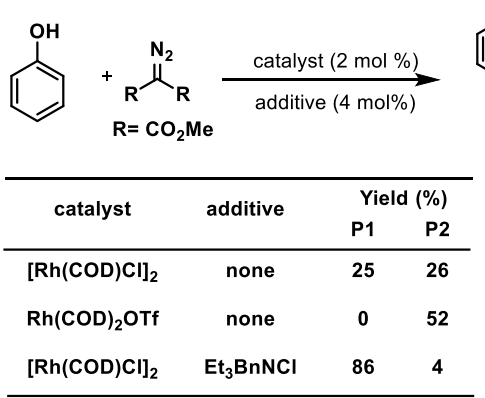

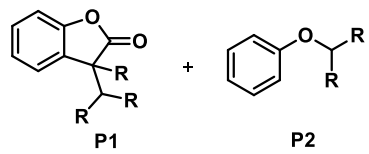

Proposed key intermediate:

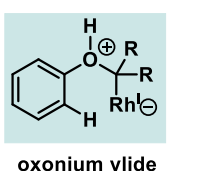

c) This work.: intermediate shuttles enabled by hydrogen bonds

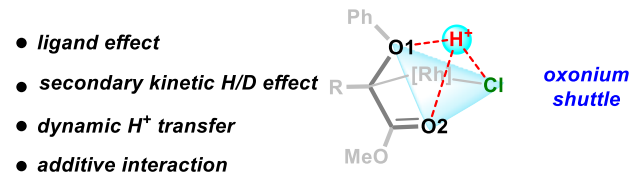

- additive interaction

- site-selectivity

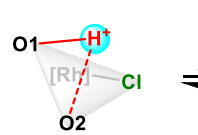

$01-\mathrm{H}---02$

C-H
insertion

O-H insertion $\sqrt{ }$

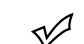

$\checkmark$
III

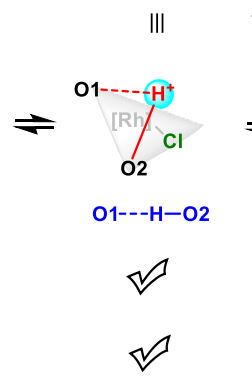

the third $\mathrm{H}^{+}$acceptor 01

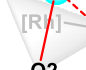

$\mathrm{O} 2-\mathrm{H}--\mathrm{Cl}$

$\checkmark$

约

Oxonium ylide type intermediate can originate from phenol type substrates. The direct catalytic functionalization of phenol is an attractive synthetic transformation that has broad applications. However, achieving high chemo- and regio-selectivity for unactivated phenol functionalization remains a significant challenge through carbene insertion. ${ }^{13-15}$ Only few carbene insertion examples by Zhang's ${ }^{16,17}$ and Shi's ${ }^{18}$ groups were reported for direct $\mathrm{C}-\mathrm{H}$ bond functionalization of phenols through gold(I) or $\mathrm{B}\left(\mathrm{C}_{6} \mathrm{~F}_{5}\right)_{3}$ catalysis. And their mechanisms, 
supported by DFT calculations, were Friedel-Crafts-type electrophilic aromatic substitution. ${ }^{19,} 20$ This is the classical carbene insertion mechanism, in which the metal valance would keep constant (Scheme 2a). Recently, Wang and coworkers reported a rare ortho-selective Rh-carbene catalyzed $\mathrm{C}-\mathrm{H}$ insertion reaction with unactivated phenol substrates (Scheme $1 \mathrm{~b}){ }^{21}$ A key oxonium ylide intermediate was proposed through control experiments that catered to our interests. However, several critical issues remain unexplored. (1) The experiment results show a vital ligand effect that have neglected by their proposed mechanism. (2) There was only indirect evidence for the viability of the oxonium ylide intermediate in the experiment. Also, it is unclear for the effect of the oxonium ylide, especially the plausible hydrogen bond involved in the reaction mechanisms. (3) What is the role of the quaternary ammonium additive? It seems to promote the $\mathrm{C}-\mathrm{H}$ insertion rather than the $\mathrm{O}-\mathrm{H}$ insertion. These questions intrigue us to perform the further mechanistic study and uncover the inscrutable site-selectivity of the catalytical reaction. A new redox forms of carbene insertion mechanisms were discovered that contrast with the typical insertion mechanisms (Scheme 2b).

Scheme 2. Different carbene insertion mechanisms.

a) Classical carbene $X-H$ insertion
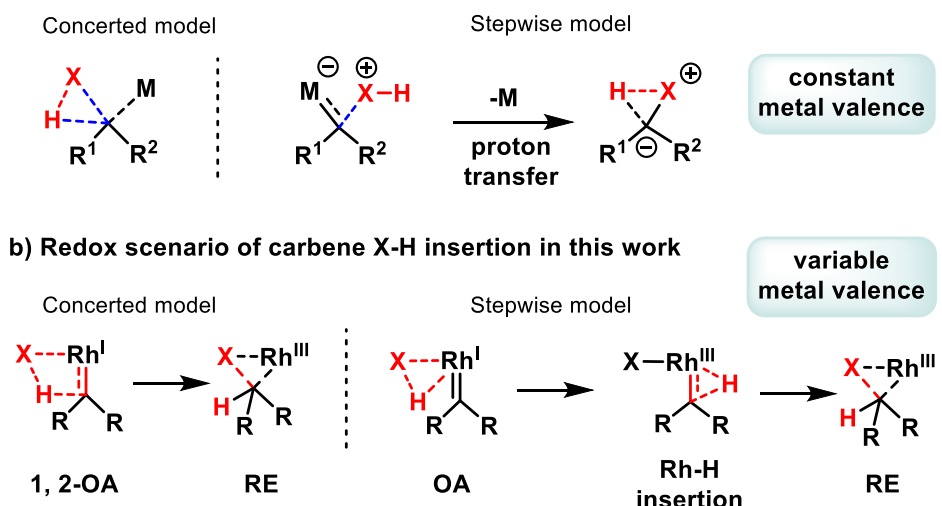

Detailed mechanistic studies for organic reactions by computational chemistry have become increasingly reliable. ${ }^{22,23}$ Notably, quasi-classical direct dynamics simulations have been applied in interpreting organic reactions that cannot be well described by classic transition state theory (TST) like bifurcating surface, etc. ${ }^{24-30}$ Herein, we perform quantum mechanics calculations and quasi-classical direct dynamics simulations to uncover dynamic hydrogen bonds, enabled by $\mathrm{Cl}^{-}$ anion, control the catalytic reactivity and selectivity of unactivated phenol alkylation (Scheme 1c). Also, the pathway motion of hydrogen bonds coupling with the Rh-C cleavage was revealed, 
suggesting an important dynamics effect in this reaction. The seemingly facile and negligible effects were vital to achieve highly efficient reactions, which were previously found by us in flexible conformational changes. ${ }^{31,32}$ The dynamic proton transfer mechanism in oxonium ylide lead to an intermediates shuttle that unexpectedly facilitate the reaction and effect the site-selective $\mathrm{C}-\mathrm{H}$ or $\mathrm{O}-\mathrm{H}$ insertion.

\section{Results and discussion}

\section{a. Mechanism for phenol functionalization via an oxonium ylide intermediate}

For phenol functionalization by the catalytic Rh-carbene intermediate, oxonium ylide intermediate affords two possibility for either $\mathrm{O}-\mathrm{H}$ insertion or $\mathrm{C}-\mathrm{H}$ insertion (Scheme 3). The O$\mathrm{H}$ insertion mechanism will follow the classical stepwise insertion in Scheme 2a. ${ }^{11,12}$ For the carbene $\mathrm{C}-\mathrm{H}$ insertion pathway, two major mechanisms include redox models and classical stepwise model. The initial $\mathrm{C}-\mathrm{H}$ activation occurs via oxidative addition (OA) of $\mathrm{Rh}^{\mathrm{I}}$ carbene species ${ }^{33-36}$ or a 1,2- oxidative addition ${ }^{37}$ of $\mathrm{Rh}=\mathrm{C}$ bond. The resulting intermediates will undergo carbene migratory insertion, ${ }^{38,39}$ and then terminate by the reductive elimination to form insertion products. $^{40,41}$ Alternatively, the mechanism may follow the classical stepwise model via Friedel-Crafts-type electrophilic aromatic attacking ( $\left.\mathrm{S}_{\mathrm{E}} \mathrm{Ar}\right) .{ }^{19,}{ }^{20,} 42$

Scheme 3. The proposed mechanisms for carbene $\mathrm{C}-\mathrm{H}$ and $\mathrm{O}-\mathrm{H}$ insertion products.

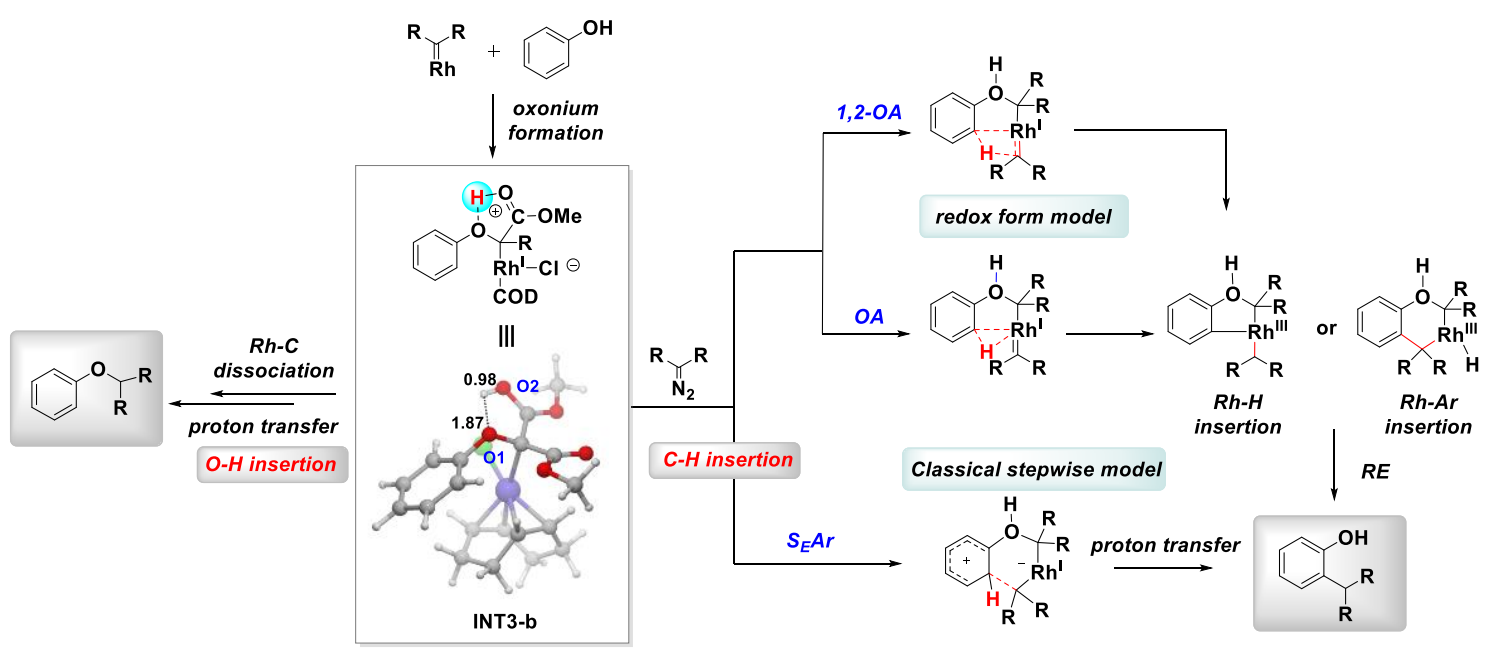

Density functional theory (DFT) calculations were performed on the proposed catalytic cycle by four types of ligand coordination models (vide infra and see ESI Figure S5-S9 for details). The most favorable energy profiles are charge separated models involving $\mathrm{Cl}^{-}$coordination with $\mathrm{Rh}$, as 
shown in Figure 1. The active catalyst INT2 is generated from the dissociation of the dimeric catalyst precursor $[\mathrm{Rh}(\mathrm{COD}) \mathrm{Cl}]_{2}$. After a slightly exothermic process for carbene formation $(-3.4$ $\mathrm{kcal} / \mathrm{mol}$ ), ${ }^{43}, 44$ the resulting metal carbene and phenol overcome an energy barrier (TS0) of 20.6 $\mathrm{kcal} / \mathrm{mol}$ to give the metal-associated oxonium ylide intermediate (INT3-b). Subsequently, the reaction with another diazo complex 1 will lead to pseudo zwitterionic INT4 that is endothermic for $2.6 \mathrm{kcal} / \mathrm{mol}$ from INT3-b.

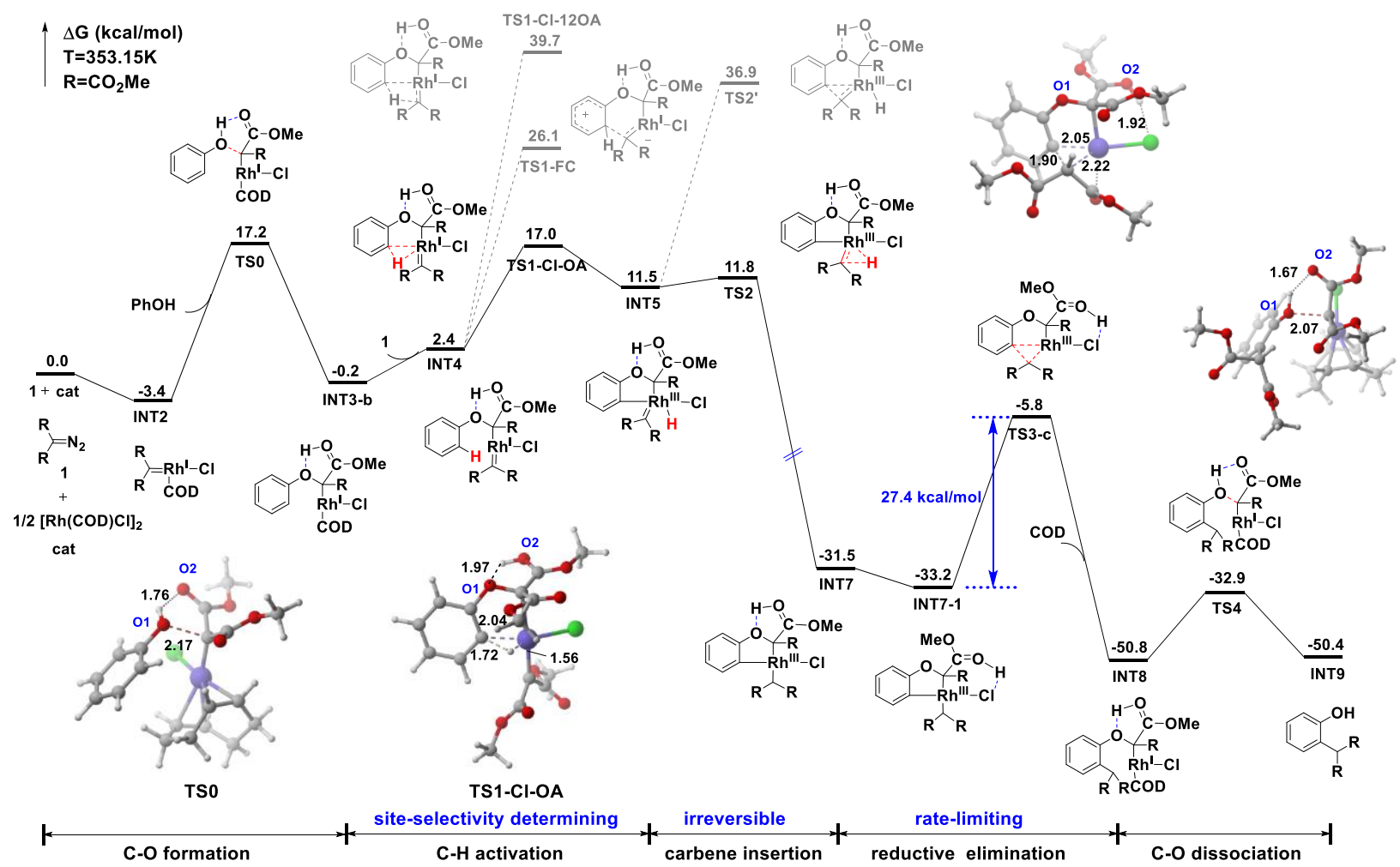

Figure 1. Computed Gibbs free energy (in $\mathrm{kcal} / \mathrm{mol}$ ) profiles for the complete catalytic cycle. Distances are in $\AA$. Computed at the SMD (toluene)/ $\omega$ B97X-D/def2-TZVPP $/ / \omega B 97 X-$ D/LANL2DZ-6-31G(d) level.

The bifunctional INT4 with both oxonium ylide and carbene group can undergo either redox $\mathrm{C}-\mathrm{H}$ activation or classical $\mathrm{C}-\mathrm{C}$ bond formation (see the complete energy profiles in Figure S1). The C-H activation via TS1-Cl-OA or TS1-Cl-12OA transition states give an ortho metalation compound. In TS1-Cl-OA, the oxidative addition of $\mathrm{C}-\mathrm{H}$ bond by rhodium species leads to rhodacycle carbene INT5, ${ }^{45,} 46$ followed by irreversible carbene insertion of Rh-H via TS2 affording INT7. We also investigated that Rh-aryl migratory insertion of INT5 via TS2' is unfavorable with a barrier of $40.3 \mathrm{kcal} / \mathrm{mol}$. Although the 1,2-oxidative addition via a concerted TS1-CI-12OA can directly lead to rhodacycle INT7, the overall barrier of TS1-Cl-OA is 22.7 
$\mathrm{kcal} / \mathrm{mol}$ more favorable than that of TS1-Cl-12OA. However, it could be changed by ligand effects (vide infra). We also calculated the $\mathrm{Cl}^{-}$ligand involved models in the $\mathrm{C}-\mathrm{H}$ activation step via concerted metalation-deprotonation (CMD) model, which was not favorable pathway due to a weak Lewis base for the $\mathrm{Cl}^{-}$anion (see Figure S3). In addition, the energy barrier of C-C bond formation by electrophilic aromatic substitution via TS1-FC is $29.5 \mathrm{kcal} / \mathrm{mol}$, which can be ruled out. The calculated barrier indicated the oxidative $\mathrm{C}-\mathrm{H}$ activation is kinetically more favorable than the classical $S_{E} A r$ mechanism. More transition states without forming oxonium ylide were also calculated, and the exteremly high energy barrier (>50 kcal/mol, see Figure S1) imply the importance of such intermediates. After the irreversible carbene insertion of Rh-H via TS2, the forming INT7 with O1...H-O2 hydrogen bond will isomerize to INT7-1 with new formed O2H...Cl interaction. The reductive elimination via TS3-c is a probable rate-limiting step with 27.4 $\mathrm{kcal} / \mathrm{mol}$ energy barrier, which is supported by the experimental and calculated isotop effec by using full D substituent phenol. From the scheme 4, the experimental result indicate a secondary kinetic isotopic effect and only reductive elimination step could explain the observed $\mathrm{k}_{\mathrm{H}} / \mathrm{k}_{\mathrm{D}}$ ration, see Scheme S1 and Table S1 for more details. Following the irreversible formation of INT8, the dissociation $\mathrm{C}-\mathrm{O}$ bond via a $17.9 \mathrm{kcal} / \mathrm{mol}$ energy barrier of oxonium ylide TS4 gives $\mathrm{C}-\mathrm{H}$ insertion product INT9. The following pathway to the final product P1 was shown in Figure S2. Our mechanism can also explain the different reactivity of phenol and 4-methoxyphenol, and thus are in agreement with experiments. ${ }^{21}$ And explict solvation model for key steps were also tested as shown in Table S10, which would not change our conclusion.

Scheme 4. Kinetic isotope effects by experiment and calculations.
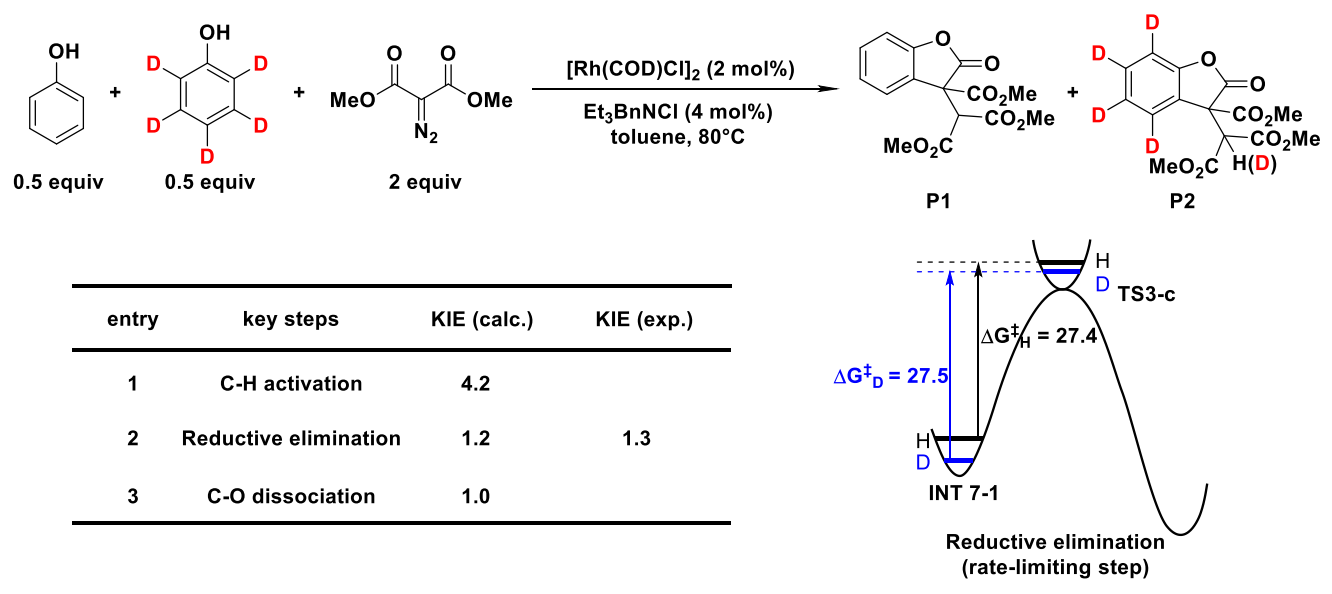


\section{b. Ligand and hydrogen bond effects for the reactivity of $\mathrm{C}-\mathrm{H}$ functionalization.}

Ligand effects: Our calculated results for the reactivity significantly relied on ligands and $\mathrm{Cl}^{-}$anion has key effect for the reaction. Activation barriers of major steps for C-H activation and C-C formation have been computed with the dependency of ligands and charge: null/cation (the experiment proposed model), $\mathrm{COD} /$ cation, $\mathrm{Cl}^{-} /$neutral and $\mathrm{COD}-\mathrm{H}^{+} /$neutral (Figure 2). Changing the mechanistic model from neutral to cation species will dramatically increase the activation barrier, suggesting the unfavorable dissociation of the $\mathrm{Cl}^{-}$anion from the $\mathrm{Rh}^{\mathrm{I}}$ center (see Scheme $\mathrm{S} 3$ ). In the neutral models, it was the $\mathrm{Cl}^{-}$ligand model of oxonium ylide species that forms the type of pseudo zwitterion facilitated the reaction rather than that through the COD model, especially for the rate-limiting step in the C-C formation. As shown in Figure 2, the Csp ${ }^{2}$-Csp $p^{3}$ reductive elimination (III) and the carbene insertion into Rh-aryl bond (IV) were investigated for C-C formation. The calculated results indicated the $\mathrm{RE}(\mathrm{III})$ is more favorable with a relatively low energy barrier $(27.4 \mathrm{kcal} / \mathrm{mol})$ with $\mathrm{Cl}^{-}$coordination. Although the neutral COD- $\mathrm{H}^{+}$model tend to undergo Rh-aryl migratory insertion ${ }^{38}$, more calculated results indicated the migratory carbene insertion of this reaction at the $\mathrm{Rh}-\mathrm{H}$ bond is favored than the insertion at $\mathrm{Rh}$-aryl bond, see Figure S6-S9 for details. After Rh-H migrated insertion, the resulting intermediate INT7 is the precursor for the accessible RE(III) in this redox carbene insertion, while the common Rh-aryl migratory insertion (IV) is ruled out.

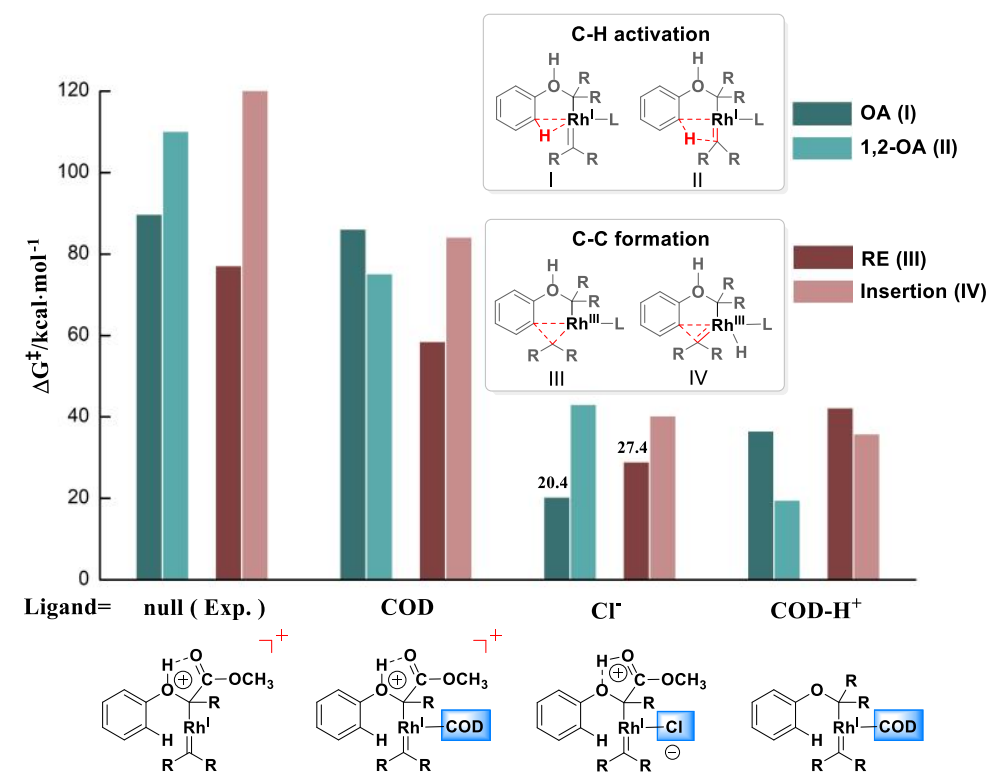

Figure 2. Ligands and charge effect on mechanism models and activation barriers. 
a)

\begin{tabular}{|c|c|c|c|c|c|c|c|c|c|c|}
\hline \multirow{3}{*}{ H } & \multirow{2}{*}{ Ligand } & \multicolumn{4}{|c|}{ NPA charge } & \multicolumn{5}{|c|}{ Bond distance } \\
\hline & & Rh & H & C1 & C2 & Rh-C1 & Rh-H & Rh-C2 & $\mathrm{C} 1-\mathrm{H}$ & $\mathrm{C} 2-\mathrm{H}$ \\
\hline & null & 0.369 & 0.231 & -0.198 & -0.046 & 2.00 & 1.56 & 1.90 & 1.68 & 2.40 \\
\hline & COD & 0.358 & 0.212 & -0.283 & 0.023 & 2.08 & 1.58 & 1.87 & 1.58 & 2.34 \\
\hline & $\mathrm{Cl}^{-}$ & 0.310 & 0.199 & -0.231 & 0.041 & 2.04 & 1.56 & 1.86 & 1.72 & 2.40 \\
\hline OA & $\mathrm{COD}-\mathrm{H}^{+}$ & 0.349 & 0.206 & -0.260 & -0.057 & 2.07 & 1.59 & 1.90 & 1.57 & 2.38 \\
\hline & & \multicolumn{4}{|c|}{ NPA charge } & \multicolumn{5}{|c|}{ Bond distance } \\
\hline & Ligand & $\mathbf{R h}$ & H & C1 & C2 & Rh-C1 & Rh-H & Rh-C2 & $\mathrm{C} 1-\mathrm{H}$ & $\mathrm{C} 2-\mathrm{H}$ \\
\hline & null & 0.822 & 0.355 & -0.425 & -0.430 & 2.07 & 1.96 & 2.00 & 1.23 & 1.81 \\
\hline 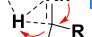 & COD & 0.682 & 0.330 & -0.402 & -0.428 & 2.29 & 1.92 & 2.13 & 1.22 & 1.61 \\
\hline $\mathbf{R}$ & $\mathrm{Cl}^{-}$ & 0.807 & 0.329 & -0.415 & -0.471 & 2.20 & 1.78 & 2.07 & 1.31 & 1.61 \\
\hline 1,2-OA & COD-H ${ }^{+}$ & 0.670 & 0.328 & -0.391 & -0.536 & 2.26 & 1.89 & 2.16 & 1.24 & 1.61 \\
\hline
\end{tabular}
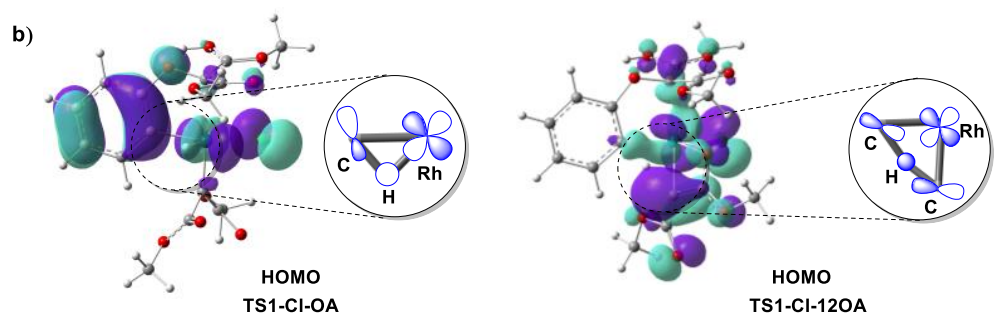

Figure 3. a) Selected NPA charge and bond distances of calculated transition states. b) Frontier molecular orbitals of calculated transition states for OA and 1,2-OA model.

For the site-selective determining step, the activation barriers of $\mathrm{C}-\mathrm{H}$ activation step are highly related to the coordination of different ligands. Oxidative addition (OA) via threemembered ring mechanism(I) is favorable in the $\mathrm{Cl}^{-}$model or null model of Figure 2, while models with COD ligand favor an unusual 1,2-OA(II) forming four-membered ring. To understand these ligand effects, calculated structures and NPA charge of transition states were shown in Figure $3 a$. From transition states of the 1,2-OA(II), the carbene can mediate the oxidative addition with $\mathrm{Rh}$ back donation to the carbene atom, giving shorter $\mathrm{C}-\mathrm{H}$ and longer $\mathrm{Rh}-\mathrm{H} / \mathrm{Rh}-\mathrm{C}$ bond lengths than that in $\mathrm{OA}(\mathrm{I})$. This mechanism is likely to be an oxidative form of concerted metalationdeprotonation or a concerted model of three-membered ring $\mathrm{OA}(\mathrm{I})$ followed by a Rh-H migration. From the charge distribution of TSs in 1,2-OA(II), low covalent Rh transfers electrons to Ccarbene acting an oxidizer, and the developing negative charge on $\mathrm{C}$-carbene is stabilized by the hydrogen on the ortho-arene. In TSs of OA(I) model, the carbene group slightly donates electron to the metal, and the $\mathrm{Rh}^{\mathrm{I}}$ takes the responsibility of the oxidative addition of ortho-arene-H bond. These results can also be supported by the frontier molecular orbital analysis, in which the $\sigma^{*}$ orbital of $\mathrm{C}-\mathrm{H}$ bond dominantly interacted with the $\mathrm{Rh} \mathrm{d}$ orbital in the OA or the carbene $\pi$ orbital 
in the 1,2-OA as shown in Figure 3b. Therefore, ligand effect causing the electron transfer from $\mathrm{Rh}$ to carbene will make for the 1,2-OA(II) mechanism and vice versa.

Hydrogen bond effects: Since the favorable reaction model is the oxonium ylide with $\mathrm{Cl}^{-}$ ligand coordination, the bifunctional chloride ion can also display as a hydrogen bond acceptor. The oxonium ylide can form multiple hydrogen bonds that may influence the reactivity of $\mathrm{C}-\mathrm{H}$ activation and reductive elimination. Therefore, four possible hydrogen bonds were considered among oxonium, esters and $\mathrm{Cl}^{-}$in Figure 4a. The triangle form of proton accepters enabled by $\mathrm{Cl}^{-}$ anion might stabilize oxonium intermediates (see Figure S10). Initially, electrostatic potential map of each model INT3s indicate the large charge separation for INT3-a/INT3-b and the relative charge equalization for INT3-c/INT3-d. These intermediates show varied reactivities in the key step of this reaction, although such differences of hydrogen bond interaction seems to have been neglected in the study of the mechanisms. ${ }^{11,12}$ Based on each intermediate from INT3-b to INT3d (INT3-a is ruled out due to high relative free energy), the corresponding energy barrier (Figure $4 \mathrm{~b})$ were calculated for $\mathrm{C}-\mathrm{H}$ activation and reductive elimination (RE) steps. The $\mathrm{C}-\mathrm{H}$ activation favors B model (INT3-b) with O1...H-O2 hydrogen bond as an active species that can facilitate the oxidative addition of $\mathrm{C}-\mathrm{H}$ bond with $20.4 \mathrm{kcal} / \mathrm{mol}$ barrier, while the $\mathrm{C}$ model (INT3-c) with $\mathrm{O} 2-\mathrm{H} \ldots \mathrm{Cl}$ hydrogen bond is responsible for the reductive elimination of the $\mathrm{C}-\mathrm{C}$ formation (27.4 $\mathrm{kcal} / \mathrm{mol}$ ). These results could be attributed to charge separation of intermediates. Both of $\mathrm{C}-\mathrm{H}$ activation and RE steps, energy barriers $\left(\Delta G^{\sharp}\right)$ are well correlated with the dipole moment $\Delta \mu$. $\Delta \mathrm{G}^{\ddagger}$ is inversely associated with $\Delta \mu$, indicating that increasing the dipole would benefit both oxidative addition and reductive elimination steps.

Moreover, the early transition state of $\mathrm{C}-\mathrm{C}$ reductive elimination can be formed within increased dipole moment species (see Figure $\mathrm{S} 4$ ), which could be ascribed to the reducing capacity of $\mathrm{Rh}^{\mathrm{III}}$ has been enhanced by the high polar $\mathrm{Rh}-\mathrm{Cl}$ bond and the $\mathrm{O} 2-\mathrm{H} . . . \mathrm{Cl}$ hydrogen bond. Generally, these proton transfers driven by diverse modes $(\mathrm{O} 1-\mathrm{H} \ldots \mathrm{O} 2, \mathrm{O} 1 \ldots \mathrm{H}-\mathrm{O} 2, \mathrm{O} 2-\mathrm{H} \ldots \mathrm{Cl})$ of hydrogen bonds may contribute catalytic reactivities through the tunable charge separation or dipole moment of oxonium ylide intermediates. We then conclude that the $\mathrm{Cl}^{-} /$neutral model with the charge separation is responsible for this new carbene redox insertion. $\mathrm{Cl}^{-}$as a weak electronfield ligand displays a significant negative charge contribution to the Rh complex, which is also a pivotal hydrogen bond accepter to facilitate the catalytic reaction. 
a)

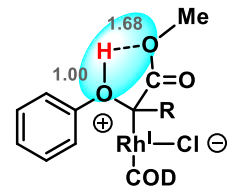

INT3-a

$16.2 \mathrm{kcal} / \mathrm{mol}$

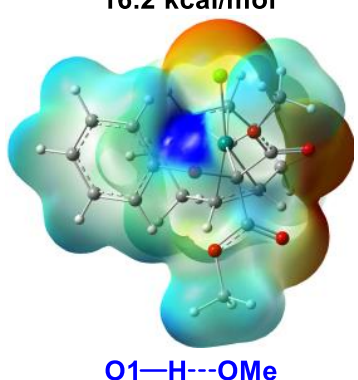

O1-H---OMe

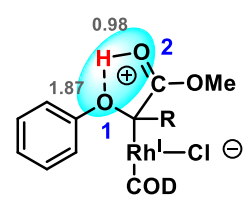

INT3-b

$-0.2 \mathrm{kcal} / \mathrm{mol}$

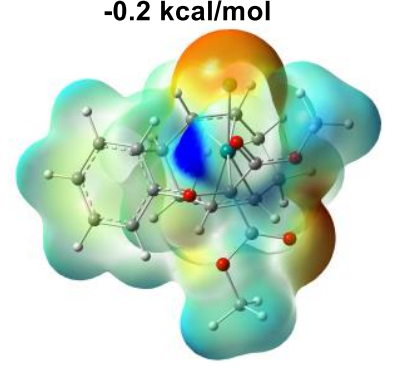

O1---H-O2

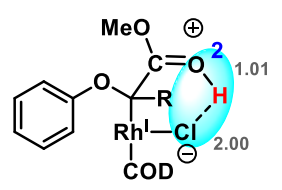

INT3-C

$-4.9 \mathrm{kcal} / \mathrm{mol}$

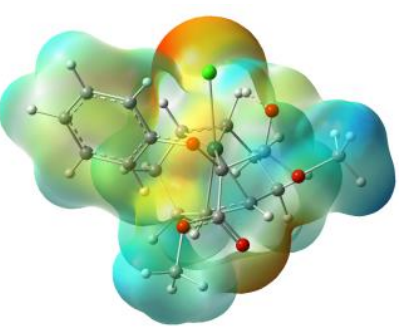

$\mathrm{O} 2-\mathrm{H}---\mathrm{Cl}$

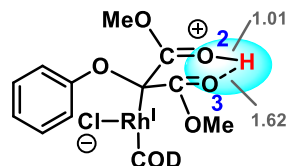

INT3-d

$-7.2 \mathrm{kcal} / \mathrm{mol}$

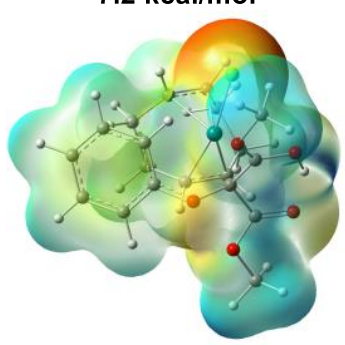

$\mathrm{O} 2-\mathrm{H}---\mathrm{O} 3$

b)
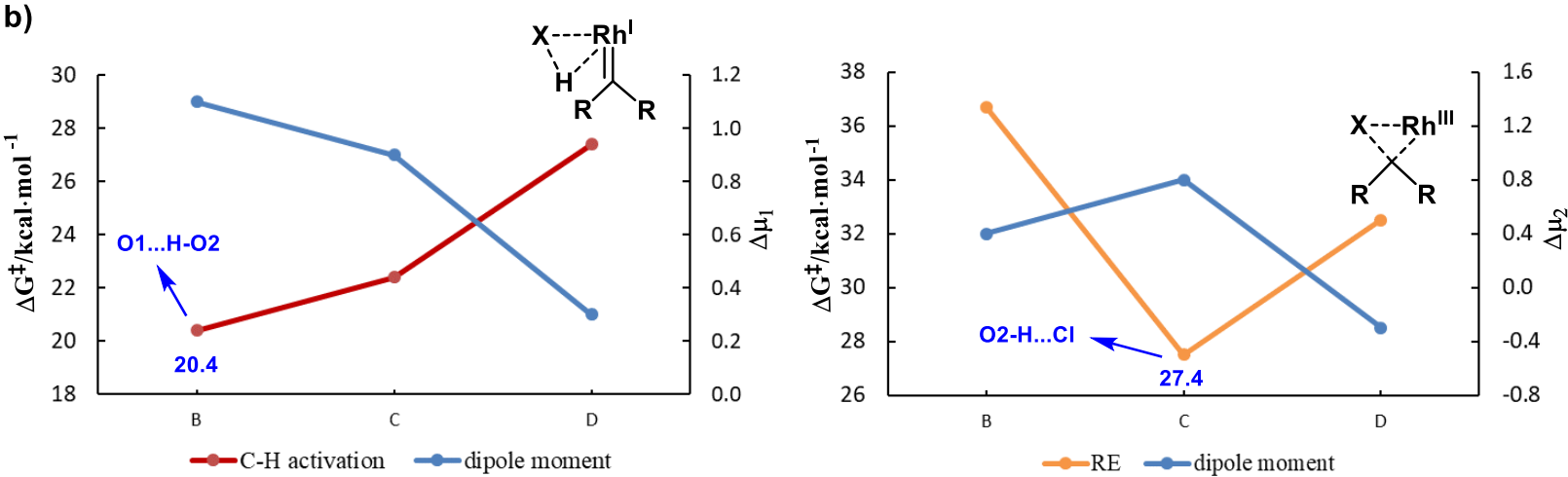

Figure 4. Reactivity control of diverse hydrogen bonds. a) Electrostatic potential map of INT3a-d with iso-value $=0.004$ b) The energy barriers and differences of the dipole moment between intermediate and transition state $(\Delta \mu)$ in different hydrogen models. $\mathrm{B}, \mathrm{C}$ and $\mathrm{D}$ on $\mathrm{x}$-axis corresponding to oxonium ylide models INT3-b, INT3-c, INT3-d, respectively. $\left(\Delta \mu_{1}=\Delta \mu_{\mathrm{TS} 1}{ }^{-}\right.$ $\left.\Delta \mu_{\mathrm{INT} 4}, \Delta \mu_{2}=\Delta \mu_{\mathrm{TS} 3}-\Delta \mu_{\mathrm{INT} 7}\right)$

\section{c. Dynamic effects of hydrogen bonds in oxonium ylide intermediates}

Although diverse modes $(\mathrm{O} 1-\mathrm{H} \ldots \mathrm{O} 2, \mathrm{O} 1 \ldots \mathrm{H}-\mathrm{O} 2, \mathrm{O} 2-\mathrm{H} \ldots \mathrm{Cl})$ of hydrogen bonds in oxonium intermediates may influence the calculated energy barriers of $\mathrm{C}-\mathrm{H}$ activation and reductive elimination, whether these corresponding intermediates can be linked together that remained unclear and became essential to finally achieve this catalytic reaction. Therefore quasi-classical direct dynamics trajectories were introduced under conditions involving implicit or explicit solvation and quaternary ammonium salt $\left(\mathrm{Me}_{4} \mathrm{NCl}\right)($ Scheme 5$) .{ }^{47}$ Vibrational averaged velocity distributions of quasi-classical trajectories were initiated from transition state TS0-1 of proton transfer between $\mathrm{O} 1$ and $\mathrm{O} 2$ that propagated forward (dark red) and backward (light blue). These 
simulations indicated the important role of $\mathrm{Me}_{4} \mathrm{NCl}$ additive to inhibit the $\mathrm{O}-\mathrm{H}$ insertion, and trajectories $\mathrm{C}$ would become dominant at model Sol1 without $\mathrm{Me}_{4} \mathrm{NCl}$ interaction.

Scheme 5. Results from quasi-classical trajectories starting from transition state TS0-1 at the $\omega B 97 X-D / 6-31 G(d) / L A N L 2 D Z$ level of theory.
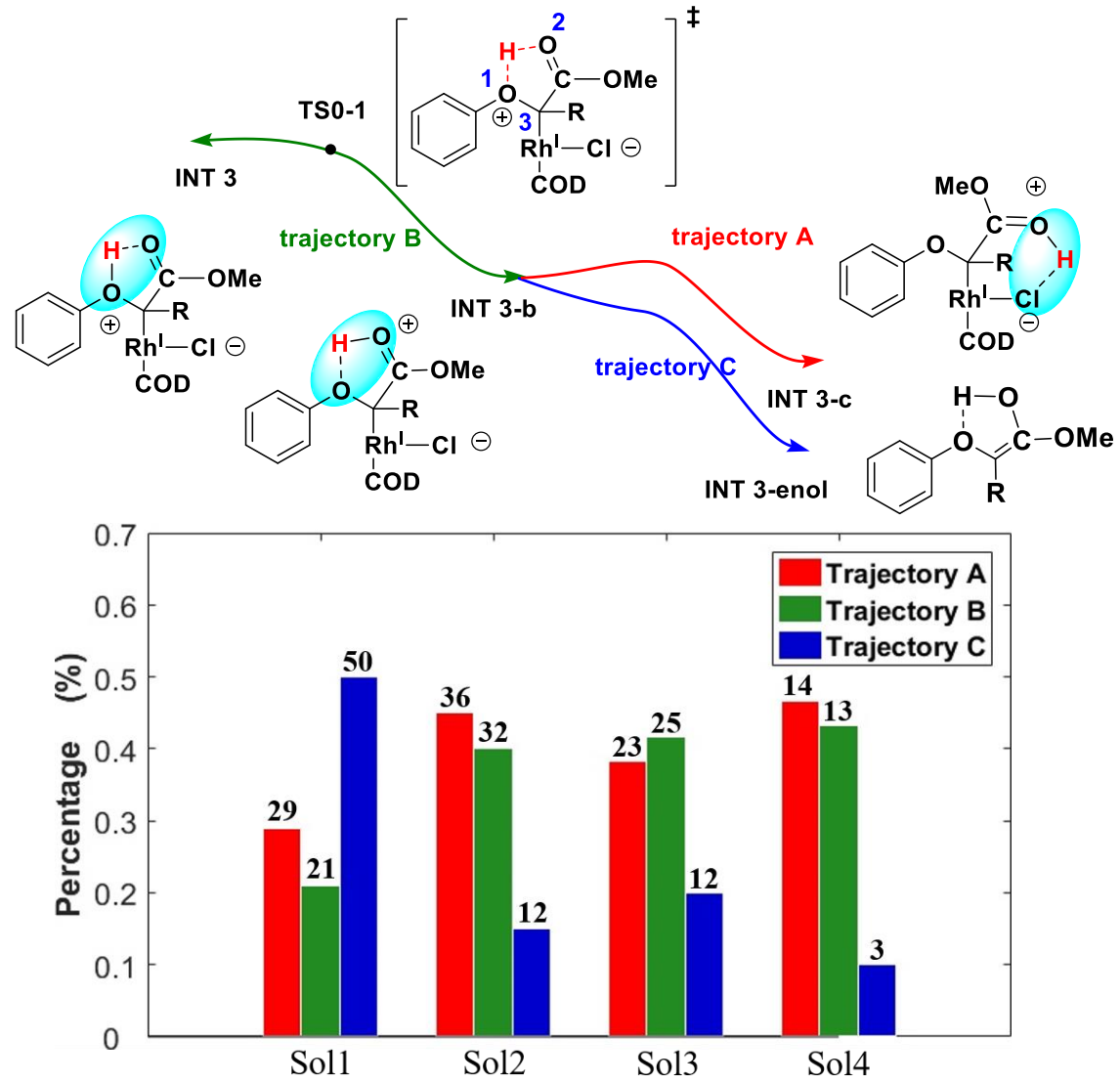

Sol1 Trajectories without $\mathrm{Me}_{4} \mathrm{NCl}$ additive

Sol2 Trajectories with $\mathrm{Me}_{4} \mathrm{NCl}$ additive

Sol3 Trajectories with $\mathrm{Me}_{4} \mathrm{NCl}$ additive and one toluene explicit molecule

Sol4 Trajectories with $\mathrm{Me}_{4} \mathrm{NCl}$ additive in $17 \AA \times 15 \AA$ x $12 \AA$ explicit toluene solvent

To consider explicit solvent interaction, we firstly initiate 60 trajectories considering both $\mathrm{Me}_{4} \mathrm{NCl}$ additive and one explicit toluene solvation (Sol3 in Scheme 5). And around 80\%, 48 out of 60 trajectories was found to have motion along the local minimum energy pathway to Type A and B trajectories, which is comparable to the implicit solvent model (Sol2 in Scheme 5). Then, more explicit solvent molecules in $17 \times 15 \times 12 \AA^{3}$ box (Sol 4) were evaluated, especially for involving extra toluene solvent around our H-bonding region to better evaluate the explicit solvent interaction. The result indicated the $\mathrm{H}$-bond interaction was not perturbed, and sufficient trajectory A and B (90\%) were located. This is probably because toluene using in the experiment is very weak polar solvent and would not affect the H-bond interaction very much. However, the Rh-C 
dissociation pathway of $\mathrm{O}-\mathrm{H}$ insertion (trajectory $\mathrm{C}$ ) would be inhibited by explicit toluene molecules around, which rationalize the experiment observation.

Table 1. Results from quasi-classical trajectories starting from transition state TS0-1 under Sol2 model. Trajectories numbers with median time (in parentheses) for forming each intermediate and transition state. Time given in femtoseconds (fs).

\begin{tabular}{cccccc}
\hline Trajectories & \multicolumn{4}{c}{ Intermediates and Transition states } & sum \\
\hline & INT3 & INT3-b & INT3-c & INT3-enol & \\
A & $19(3)$ & $36(18)$ & $36(339)$ & - & 36 \\
B & $20(9)$ & $32(30)$ & - & - & 32 \\
C & - & - & - & $12(306)$ & 12 \\
\hline
\end{tabular}

Since quite consistent results from Sol2 to Sol4, the simulation of Sol2 with $\mathrm{Me}_{4} \mathrm{NCl}$ additive were investigated further for detail trajectory distributions of intermediates and transition states (Table 1). The first type of trajectory A showed motions along the energy pathway affording INT3b and INT3-c with the interaction of $\mathrm{O} 1 \ldots \mathrm{H}-\mathrm{O} 2$ and $\mathrm{O} 2-\mathrm{H} \ldots \mathrm{Cl}$ hydrogen bonds, respectively, which found in 36 out of 80 trajectories $(45 \%)$ indicating their dynamical stability. Snapshots of one representative trajectory A show that the new $\mathrm{O} 2-\mathrm{H} . . . \mathrm{Cl}$ hydrogen bonds around $2.11 \AA$ were fully formed after $300 \mathrm{fs}$ in Figure 5a. The median time of trajectory A for the formation of each intermediate were shown in Table 1. All of A-type trajectories can pass INT3-b to afford INT3-c within 500fs that suggests a dynamical connection among these intermediates and the interconversion of hydrogen bonds within $\mathrm{O} 1 \ldots \mathrm{H}-\mathrm{O} 2$ and $\mathrm{O} 2-\mathrm{H} . . . \mathrm{Cl}$. This dynamical intermediate shuttle would promote the following $\mathrm{C}-\mathrm{H}$ activation and reductive elimination to fulfill the catalytic reaction. The second type of trajectories B (40\%, 32 out of 80 trajectories) was found to have motion along the local minimum energy pathway forming only INT3 and INT3-b, but fail to achieve INT3-c. The very short median times for these intermediates and no further significant structural reorganization for the remaining several hundred femtoseconds indicated that the certain stability of oxonium ylide INT3-b probably due to the $\mathrm{O} 1 \ldots \mathrm{H}-\mathrm{O} 2$ hydrogen bond interaction. The $\mathrm{Rh}(\mathrm{COD}) \mathrm{Cl}$ dissociation from the oxonium substrate, a new type of trajectory $\mathrm{C}$, was predicted during our dynamic investigation of the proton transfer step, which would lead to enolate intermediate INT3-enol (Figure 5b). The median time of the trajectories $\mathrm{C}$ for the $\mathrm{Rh}-\mathrm{C} 3$ cleavage is 306 fs that located slightly before the formation INT3-c (339 fs), suggesting the possible dynamical competition or intermediate cross with trajectories A. In snapshots of Figure 5b, the 
Rh-C3 bond is broken at around $3.0 \AA$ after $200 \mathrm{fs}$ and enolate species with $\mathrm{O} 2-\mathrm{H} . . . \mathrm{Cl}$ interaction released from $\mathrm{Rh}$ coordination in the remaining hundred femtoseconds, indicating the pathway motion coupling the proton transfer with Rh-species dissociation. In our $500 \mathrm{fs}$ simulations, neither INT3-a nor INT3-d was located as shown in Figure 4a, suggesting these intermediates might not be involved in the dynamical connection of TS0-1.

a)

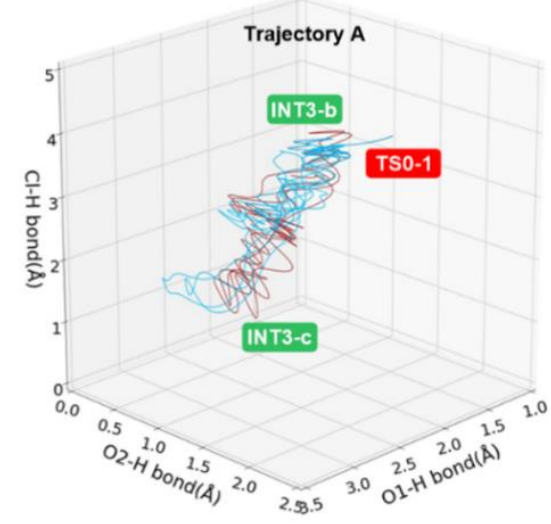

b)

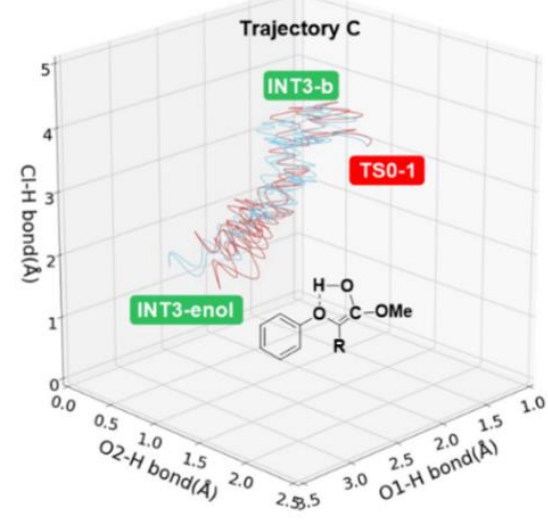

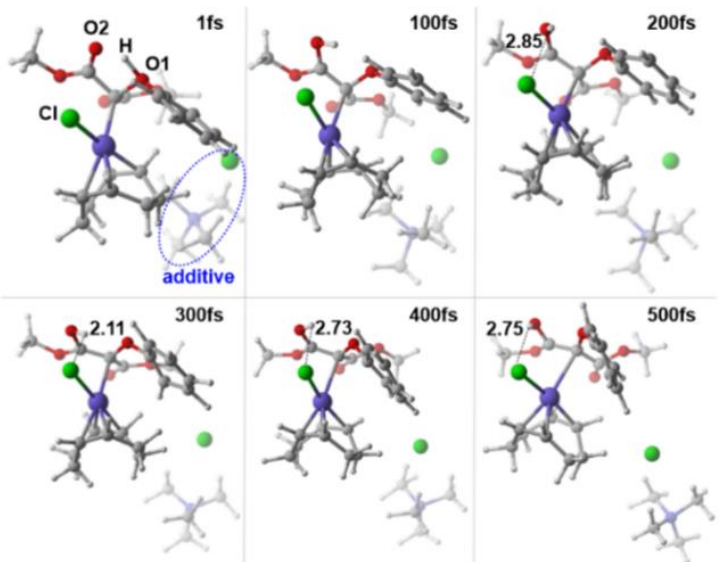

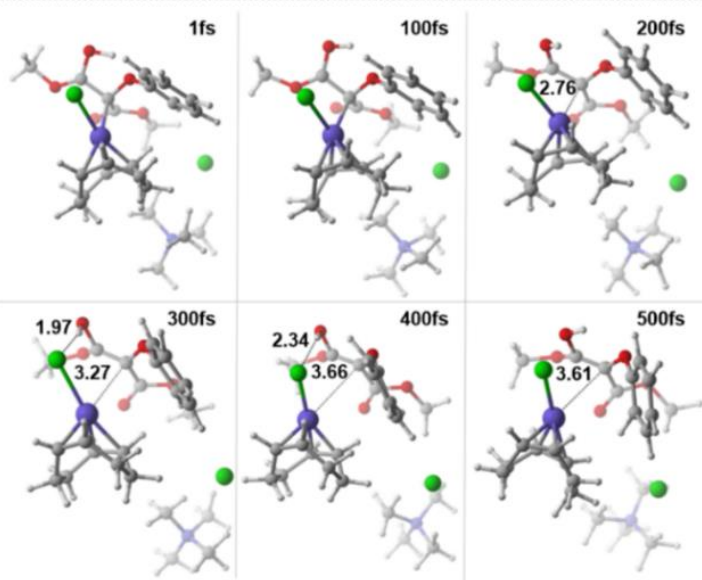

c)
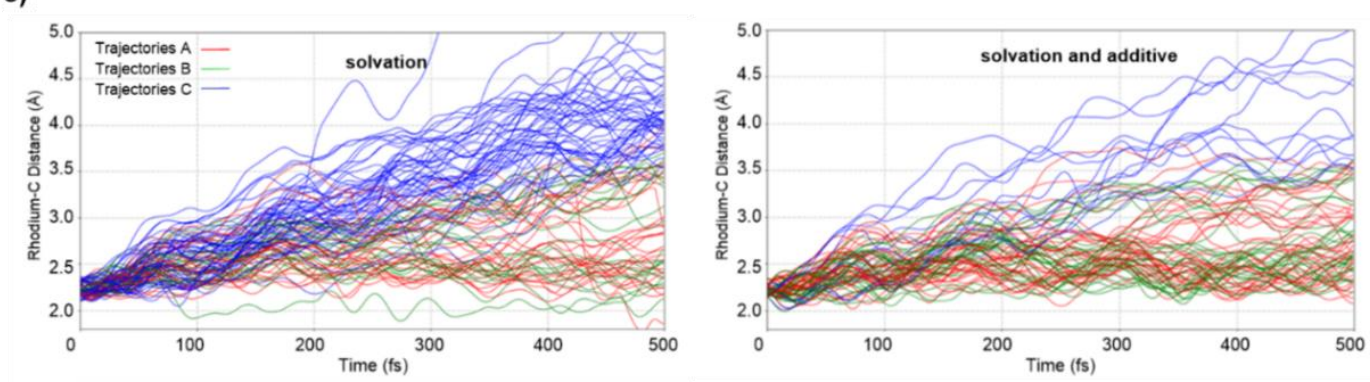

Figure 5. Quasi-classical trajectories and their snapshots with $\mathrm{Me}_{4} \mathrm{NCl}$ additive. a) A representative trajectory A. b) A representative trajectory C. c) The total trajectories illustrated based on Rh-C3 bond distances. Boundaries for bond distances of each intermediate and transition state were shown in Table S5, and the dynamic cartoon for each trajectory was added in ESI. 
Interestingly, a high additive dependency was predicted in our dynamic simulation. Solvation model with or without additive $\mathrm{Me}_{4} \mathrm{NCl}$ enable the dynamical distribution of trajectory $\mathrm{C}$ increased from $15 \%$ to $50 \%$. In contrast, trajectories A dominated in the distribution at the additive condition (45\%) that was similar with the gas phase simulation (56\%, see Table S6) as well. We suspected that in the pathway there was a possibility that hydrogen bond interaction may control the distribution. More inspections of the simulated structures indicate that 42 out of 50 trajectories (84\%) in trajectory $\mathrm{C}$ at the solvation model without additive led to form enolate intermediates with the $\mathrm{O} 1 \ldots \mathrm{H}-\mathrm{O} 2$ hydrogen bond, while 8 out of 12 trajectories forming $\mathrm{O} 2-\mathrm{H} \ldots \mathrm{Cl}$ hydrogen bond became dominant with $67 \%$ distribution under the additive $\mathrm{Me}_{4} \mathrm{NCl}$ condition. We thus speculate the $\mathrm{O} 2-\mathrm{H} \ldots \mathrm{Cl}$ interaction as a linker of two fragments may inhibit the $\mathrm{Rh}$ species dissociation that could also be verified by time plot of Figure $5 \mathrm{c}$. The majority of trajectory $\mathrm{C}$ tend to dissociate the Rh species with the Rh-C3 distance $>3.5 \AA$ after around $350 \mathrm{fs}$, suggesting the irreversible formation of INT3-enol. The $\mathrm{O} 2-\mathrm{H} \ldots \mathrm{Cl}$ interaction of trajectory $\mathrm{C}$ at the additive condition may restrict the Rh-C3 distance $<3.5 \AA$ that provide a reversible potential to form INT3c or INT3-b (Figure 5c). Moreover, INT3-b/c and INT3-enol are key precursors for C-H and O$\mathrm{H}$ insertion, respectively. Therefore, our quasi-classical direct dynamics simulations under different solvation model have confirmed not only the facile motion coupling among oxonium ylide intermediates at secondary coordination sphere, ${ }^{48,} 49$ but also $\mathrm{O} 1 \ldots \mathrm{H}-\mathrm{O} 2 / \mathrm{O} 2-\mathrm{H} \ldots \mathrm{Cl}$ hydrogen bonds of the key intermediates control site-selective phenol alkylation.

\section{d. The validation of the site-selective phenol functionalization from the competitive $\mathrm{O}-\mathrm{H}$ insertion.}

Considering the impact of dynamic hydrogen bonds in the highly competitive O-H insertion of phenol functionalization, the resulting oxonium ylide INT3-b would undergo Rh-C3 bond cleavage to mainly afford enol intermediate. As shown in Figure 6a, the Rh-complex was fully dissociated to form the INT3-enol that is thermodynamically favorable. Furthermore, through our previous dynamic simulations, INT3-b with the $\mathrm{O} 1 \ldots \mathrm{H}-\mathrm{O} 2$ interaction may lead the $\mathrm{Rh}$ species dissociation to INT3-enol, probably because the developing C-C $\pi$ bond of the enol model will destabilize Rh-C3 $\sigma$-bond. In the following mechanism of ester-enol tautomerism, the intermolecular proton transfer of INT3-enol by an additional phenol as a proton shuttle reagent was favored with $19.8 \mathrm{kcal} / \mathrm{mol}$ energy barrier via transition state TS6, indicating the phenol has 
the dual roles. ${ }^{50,51}$ This proton source assisted mechanism was in agreement with the metal carbenoid $\mathrm{O}-\mathrm{H}$ insertion. ${ }^{11,12}$ The 1,2-oxidative addition might be the second potential pathway with $23.8 \mathrm{kcal} / \mathrm{mol}$ activation barrier. ${ }^{37}$ Direct intramolecular H-transfers from INT3-enol are unfavorable due to high energy barrier for the 55.1 and $42.6 \mathrm{kcal} / \mathrm{mol}$ in $1,2-\mathrm{H}$ and 1,3-H shift, respectively. Furthermore, the favorable pathway for $\mathrm{O}-\mathrm{H}$ insertion is slightly more competitive than that for the $\mathrm{C}-\mathrm{H}$ insertion $(\Delta \mathrm{G}=20.4 \mathrm{kcal} / \mathrm{mol}$, see Figure 1$)$.
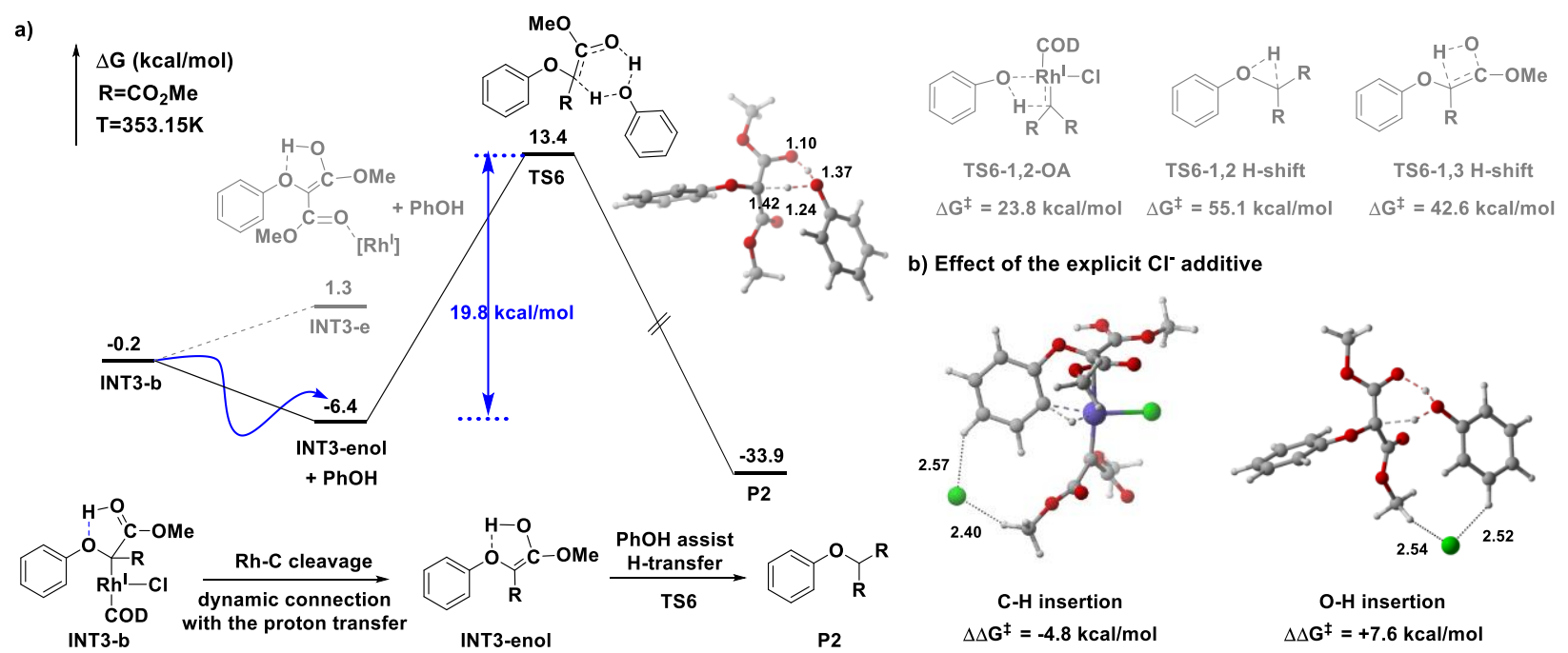

Figure 6. a) Computed Gibbs free energy (in $\mathrm{kcal} / \mathrm{mol}$ ) profiles for the $\mathrm{O}-\mathrm{H}$ insertion process with comparison of $\mathrm{C}-\mathrm{H}$ insertion. b) Relative difference of energy barriers for $\mathrm{C}-\mathrm{H} / \mathrm{O}-\mathrm{H}$ insertion in the condition of negative electric field by $\mathrm{Cl}^{-}$.

Introducing an additive $\mathrm{Me}_{4} \mathrm{NCl}$, our dynamic simulations (Figure 5) indicate the dynamic $\mathrm{H}^{+}$transfer enables INT3-b to form INT3-c stabilized by $\mathrm{O} 2-\mathrm{H} . . . \mathrm{Cl}$ hydrogen bond. This transformation would inhibit the formation of enolate intermediates and block the following $\mathrm{O}-\mathrm{H}$ insertion. To test this hypothesis, the explicit $\mathrm{Cl}^{-}$ion was introduced to evaluate the key step for C$\mathrm{H}$ and $\mathrm{O}-\mathrm{H}$ insertion as shown in Figure $6 \mathrm{~b}$. The energy barrier of $\mathrm{C}-\mathrm{H}$ activation is favorable by $4.8 \mathrm{kcal} / \mathrm{mol}$ while the $\mathrm{O}-\mathrm{H}$ insertion is inhibited by $7.6 \mathrm{kcal} / \mathrm{mol} .^{52,53}$ These calculated results are in well agreement with the experimental observation, which additive quaternary ammonium salt $\mathrm{Et}_{3} \mathrm{BnNCl}$ can facilitate the $\mathrm{C}-\mathrm{H}$ insertion product $\mathbf{P 1}$ and inhibit $\mathrm{O}-\mathrm{H}$ insertion product $\mathbf{P 2}$ (Scheme 1b). By using the catalyst $\mathrm{Rh}(\mathrm{COD})_{2} \mathrm{OTf}$ without $\mathrm{Cl}^{-}$, the reaction would no doubt lead to the oxonium ylide with only $\mathrm{O} 1 \ldots \mathrm{H}-\mathrm{O} 2$ hydrogen bond interaction that led the Rh-C3 bond cleavage to form free enol species, resulting in solely $\mathrm{O}-\mathrm{H}$ insertion product. When the catalyst $[\mathrm{Rh}(\mathrm{COD}) \mathrm{Cl}]_{2}$ and $\mathrm{Et}_{3} \mathrm{BnNCl}$ were applied to the reaction, dynamic proton transfers indicated 
original oxonium ylides would convert to intermediates with $\mathrm{O} 2-\mathrm{H} \ldots \mathrm{Cl}$ interaction that would facilitate $\mathrm{C}-\mathrm{H}$ insertion product by inhibiting the formation of free enol species. Our dynamic simulations predict that no more than $15 \%$ product will undergo $\mathrm{O}-\mathrm{H}$ insertion pathway, which is close to the experimental product P2. The dynamic prediction for $\mathrm{C}-\mathrm{H}$ insertion product would be less than $85 \%$ that is well in agreement with the $86 \%$ in the experiment. ${ }^{21}$ Therefore, $\mathrm{the}^{-} \mathrm{Cl}^{-}$ion displaying as a key hydrogen bond accepter can stabilize the oxonium ylide intermediates and promote transition states for this $\mathrm{C}-\mathrm{H}$ insertion in $\mathrm{Rh}$ carbene catalyzed direct phenol functionalization.

\section{Conclusions}

In summary, our results describe the detailed DFT study, quasi-classical direct dynamics simulations and kinetic isotopic effect that unravel diverse and dynamic hydrogen bonds through oxonium ylide intermediates can control the reactivity and selectivity of unactivated phenol functionalization catalyzed by $\mathrm{Rh}$ carbene. A rare redox scenario of carbene insertion and mechanistic control was clarified based on key effects of ligands, hydrogen bonds and quaternary ammonium additive. As shown in Figure 7, variable forms of oxonium ylides display different functions that promote certain reaction steps for $\mathrm{C}-\mathrm{H} / \mathrm{O}-\mathrm{H}$ functionalization via carbene insertion mechanisms. The C-O formation/dissociation favors the classical oxonium ylide model with O1H...O2 hydrogen bond interaction by the adjacent ester, which display the transient directing group to catalytically coordinate and regenerate the Rh complex. The oxonium ylide intermediate with $\mathrm{O} 1 \ldots \mathrm{H}-\mathrm{O} 2$ hydrogen bond operates the oxidative addition (OA) of $\mathrm{C}-\mathrm{H}$ bond and $\mathrm{Rh}-\mathrm{H}$ carbene insertion steps along with an increased dipole moment. In addition, this oxonium ylide intermediate may dynamically undergo the Rh-C3 cleavage to afford the low dipole enol intermediates that lead to $\mathrm{O}-\mathrm{H}$ insertion product. The reductive elimination of $\mathrm{C}-\mathrm{C}$ formation as rate-limiting step requires high polar $\mathrm{Rh}-\mathrm{Cl}$ species stabilized by an $\mathrm{O} 2-\mathrm{H}$...Cl hydrogen bond of the oxonium ylide intermediate. The explicit additive can stabilize oxonium ylides with $\mathrm{O} 2-\mathrm{H} \ldots \mathrm{Cl}$ hydrogen bond interaction rather than that with the $\mathrm{O} 1 \ldots \mathrm{H}-\mathrm{O} 2$ interaction. The $\mathrm{Cl}^{-}$ligand models are crucial for acting as the hydrogen bond acceptor to facilitate the $\mathrm{C}-\mathrm{H}$ insertion and inhibit the $\mathrm{O}-\mathrm{H}$ insertion. The discovered effect of diverse hydrogen bonds probably at secondary coordination sphere may enrich the theoretical understanding not only in catalytic reaction 
mechanism but also in the accurate control of reaction selectivity through multiple hydrogen bonds acceptors, such as the bioinspired catalyst involving multiple hydrogen bond interactions. ${ }^{54}$

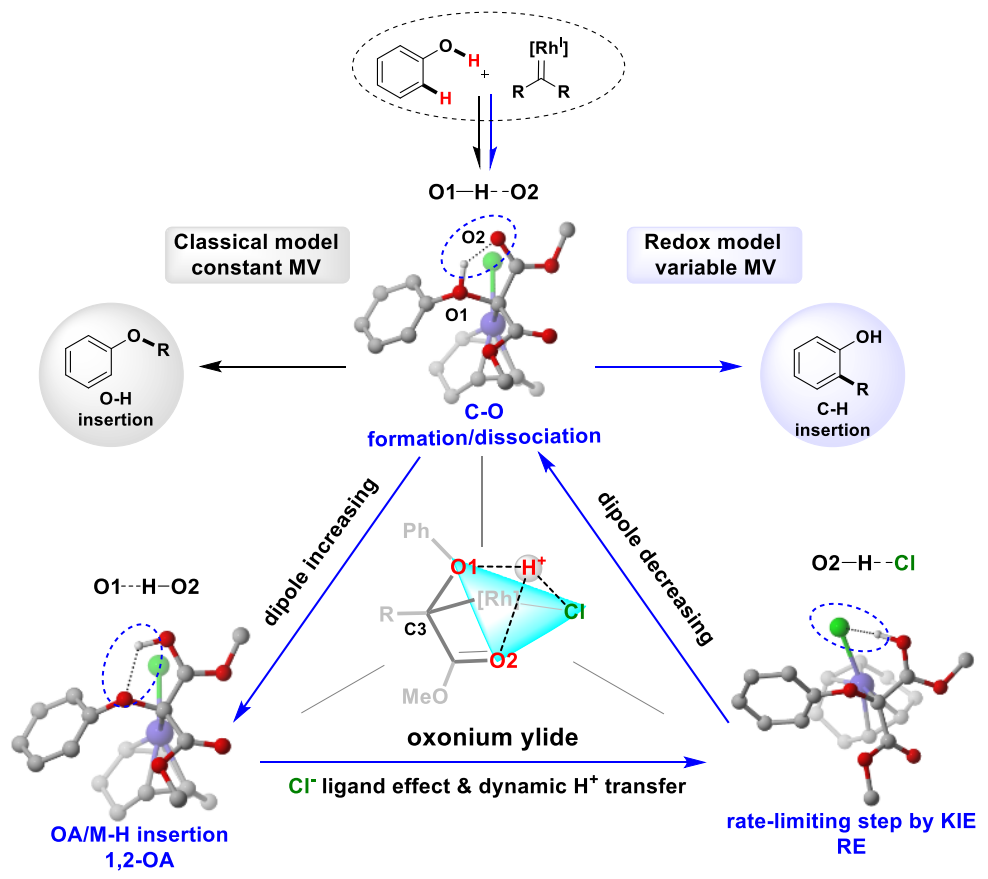

Figure 7. Redox mechanism for carbene insertions controlled by dynamic oxonium ylide intermediates. MV: Metal valance.

\section{Computational method}

All the geometry optimizations and single point energy calculations were performed by using Gaussian $09^{55}$ with the $\omega$ B97X-D ${ }^{56}$ functional. The LANL2DZ ${ }^{57}$ effective core potentials (ECPs) and basis set were used for Rh atom, and the $6-31 \mathrm{G}(\mathrm{d})^{58-60}$ basis set was used for the remainder of atoms $(\mathrm{H}, \mathrm{C}, \mathrm{O}$ and $\mathrm{Cl})$. Single point energies used the def2-TZVPP ${ }^{61,62}$ basis set for all atoms with the inclusion of $\mathrm{SMD}^{63}$ solvation model for toluene. Quasi-harmonic Gibbs free energies ${ }^{64}$ were evaluated at the reaction temperature $(353.15 \mathrm{~K})$ with rigid rotor harmonic oscillator (RRHO) vibrational entropies described by Grimme. ${ }^{65}$ More density functionals were examined for selected intermediated and transition states (see Table S11-S12). For quasi-classical direct dynamics simulations, Ess' DynSuite program ${ }^{30}$ was used to initiate a vibrationally averaged velocity distribution from TS0-1 at $353.15 \mathrm{~K}$. Each reactive trajectory was propagated forward and backward for 500 fs with 1 fs time steps in each direction under the SMD solvation model using 
the $\omega \mathrm{B} 97 \mathrm{X}-\mathrm{D} / 6-31 \mathrm{G}(\mathrm{d}) / \mathrm{LANL} 2 \mathrm{DZ}$ level of theory. Rotational energy is added to the starting conditions of the trajectory and verlet integration algorithm. The quasi-classical dynamics calculations were applied for additional explicit solvent box at the $17 \times 15 \times 12 \AA^{3}$ level. Conformational searching was performed for selected transition states and intermediates. ${ }^{66}$ The code generated during this study are available at http://dx.doi.org/10.17632/ft6fv4c $2 \mathrm{fm}$. See ESI for more computational details.

\section{Data availability}

Mechanisms of Friedel-Crafts-type electrophilic aromatic substitution ( $\mathrm{S}_{\mathrm{E}} \mathrm{Ar}$ ); isotopic experiment; original data of figures in main text; comparison results for $\omega$ B97X-D, B3LYP-D3 and M11 in reaction mechanism; detailed dynamic simulations and cartoons for trajectories; the total energies and Cartesian coordinates of calculated structures. This material is provided in the ESI.

\section{Author contributions}

Y. W. and R. L. performed the DFT calculations. K. Z. and R. L. performed the quasi-classical direct dynamics simulations. H. L., Z. S. and X. W. did the experiments. Q. P. conceived and directed the project. Y. W., R. L and Q. P. discussed the results and wrote the manuscript. Y. W., K. Z. and R. L. contributed equally.

\section{Conflicts of interest}

The authors declare no competing financial interest.

\section{Acknowledgements}

We thank Prof. Dean Tantillo and Prof. Daniel Ess for enlightening discussions. We gratefully acknowledge the National Key Research and Development Program of China (2021YFA1500100), the National Natural Science Foundation of China (92156017, 21890722 and 21950410519), the Natural Science Foundation of Tianjin Municipality (19JCJQJC62300,18JCYBJC21400), and “Frontiers Science Center for New Organic Matter”, Nankai University (Grant Number 63181206) for generous financial support. 


\section{References}

1. $\quad$ L. Pauling, Journal of the American Chemical Society, 1935, 57, 2680-2684.

2. E. N. Baker, in International Tables for Crystallography Volume F: Crystallography ofbiological macromolecules, eds. M. G. Rossmann and E. Arnold, Springer Netherlands, Dordrecht, 2001, DOI: 10.1107/97809553602060000711, pp. 546-552.

3. A. G. Doyle and E. N. Jacobsen, Chemical Reviews, 2007, 107, 5713-5743.

4. S. E. Wheeler, T. J. Seguin, Y. Guan and A. C. Doney, Accounts of Chemical Research, 2016, 49, 1061-1069.

5. B. C. Gibb, Nature Chemistry, 2020, 12, 665-667.

6. $\quad$ A. Rauwerdink and R. J. Kazlauskas, ACS Catalysis, 2015, 5, 6153-6176.

7. $\quad$ S.-F. Zhu and Q.-L. Zhou, Accounts of Chemical Research, 2012, 45, 1365-1377.

8. X. Guo and W. Hu, Accounts of Chemical Research, 2013, 46, 2427-2440.

9. P. P. Sharp, J. Mikusek, J. Ho, E. H. Krenske, M. G. Banwell, M. L. Coote, J. S. Ward and A. C. Willis, The Journal of Organic Chemistry, 2018, 83, 13678-13690.

10. C. G. Zhao, D. A. Glazier, D. Yang, D. Yin, I. A. Guzei, M. M. Aristov, P. Liu and W. Tang, Angewandte Chemie International Edition, 2019, 58, 887-891.

11. Y. Liang, H. Zhou and Z.-X. Yu, Journal of the American Chemical Society, 2009, 131, 1778317785.

12. Z.-Z. Xie, W.-J. Liao, J. Cao, L.-P. Guo, F. Verpoort and W. Fang, Organometallics, 2014, 33, 2448-2456.

13. Z. Huang and J.-P. Lumb, ACS Catalysis, 2019, 9, 521-555.

14. X. Xu and J. Luo, ChemSusChem, 2019, 12, 4601-4616.

15. H. H. Al Mamari, B. Štefane and H. B. Žugelj, Tetrahedron, 2020, 76, 130925.

16. Z. Yu, B. Ma, M. Chen, H.-H. Wu, L. Liu and J. Zhang, Journal of the American Chemical Society, 2014, 136, 6904-6907.

17. Z. Yu, Y. Li, J. Shi, B. Ma, L. Liu and J. Zhang, Angewandte Chemie International Edition, 2016, 55, 14807-14811.

18. Y. Xi, Y. Su, Z. Yu, B. Dong, E. J. McClain, Y. Lan and X. Shi, Angewandte Chemie International Edition, 2014, 53, 9817-9821.

19. Y. Liu, Z. Yu, J. Z. Zhang, L. Liu, F. Xia and J. Zhang, Chemical Science, 2016, 7, 1988-1995.

20. Q. Zhang, X.-F. Zhang, M. Li, C. Li, J.-Q. Liu, Y.-Y. Jiang, X. Ji, L. Liu and Y.-C. Wu, The Journal of Organic Chemistry, 2019, 84, 14508-14519.

21. R.-T. Guo, Y.-L. Zhang, J.-J. Tian, K.-Y. Zhu and X.-C. Wang, Organic Letters, 2020, 22, 908913.

22. P. H.-Y. Cheong, C. Y. Legault, J. M. Um, N. Çelebi-Ölçüm and K. N. Houk, Chemical Reviews, 2011, 111, 5042-5137.

23. X. Zhang, L. W. Chung and Y.-D. Wu, Accounts of Chemical Research, 2016, 49, 1302-1310.

24. D. H. Ess, S. E. Wheeler, R. G. Iafe, L. Xu, N. Çelebi-Ölçüm and K. N. Houk, Angewandte Chemie International Edition, 2008, 47, 7592-7601.

25. J. B. Thomas, J. R. Waas, M. Harmata and D. A. Singleton, Journal of the American Chemical Society, 2008, 130, 14544-14555.

26. S. R. Hare and D. J. Tantillo, Pure and Applied Chemistry, 2017, 89, 679-698.

27. Computational Organic Chemistry, 2014, DOI: https://doi.org/10.1002/9781118671191.ch8, 505567.

28. M. N. Grayson, Z. Yang and K. N. Houk, Journal of the American Chemical Society, 2017, 139, 7717-7720.

29. S. Pratihar, X. Ma, Z. Homayoon, G. L. Barnes and W. L. Hase, Journal of the American Chemical Society, 2017, 139, 3570-3590. 
30. R. Carlsen, N. Wohlgemuth, L. Carlson and D. H. Ess, Journal of the American Chemical Society, 2018, 140, 11039-11045.

31. F. Guo, Z. Yue, M. Trajkovski, X. Zhou, D. Cao, Q. Li, B. Wang, X. Wen, J. Plavec, Q. Peng, Z. $\mathrm{Xi}$ and C. Zhou, Journal of the American Chemical Society, 2018, 140, 11893-11897.

32. Q. Peng, Z. Wang, S. D. Zarić, E. N. Brothers and M. B. Hall, Journal of the American Chemical Society, 2018, 140, 3929-3939.

33. C. P. Lenges and M. Brookhart, Journal of the American Chemical Society, 1999, 121, 6616-6623.

34. B. A. Vastine and M. B. Hall, Journal of the American Chemical Society, 2007, 129, 12068-12069.

35. T. Sperger, I. A. Sanhueza, I. Kalvet and F. Schoenebeck, Chemical Reviews, 2015, 115, 95329586.

36. I. Funes-Ardoiz and F. Maseras, ACS Catalysis, 2018, 8, 1161-1172.

37. J. Becker, T. Modl and V. H. Gessner, Chemistry - A European Journal, 2014, 20, 11295-11299.

38. S. Yu, S. Liu, Y. Lan, B. Wan and X. Li, Journal of the American Chemical Society, 2015, 137, 1623-1631.

39. Y. Xia, D. Qiu and J. Wang, Chemical Reviews, 2017, 117, 13810-13889.

40. G. Lu, C. Fang, T. Xu, G. Dong and P. Liu, Journal of the American Chemical Society, 2015, 137, 8274-8283.

41. X. Qi, Y. Li, R. Bai and Y. Lan, Accounts of Chemical Research, 2017, 50, 2799-2808.

42. Y. Liu, Z. Luo, J. Z. Zhang and F. Xia, The Journal of Physical Chemistry A, 2016, 120, 64856492.

43. E. Nakamura, N. Yoshikai and M. Yamanaka, Journal of the American Chemical Society, 2002, 124, 7181-7192.

44. R. Cohen, B. Rybtchinski, M. Gandelman, H. Rozenberg, J. M. L. Martin and D. Milstein, Journal of the American Chemical Society, 2003, 125, 6532-6546.

45. X.-S. Zhang, Y. Li, H. Li, K. Chen, Z.-Q. Lei and Z.-J. Shi, Chemistry - A European Journal, 2012, 18, 16214-16225.

46. T. Shimbayashi, K. Okamoto and K. Ohe, Organometallics, 2016, 35, 2026-2031.

47. F. Liu, Z. Yang, Y. Mei and K. N. Houk, The Journal of Physical Chemistry B, 2016, 120, 62506254.

48. H. M. Colquhoun, J. F. Stoddart and D. J. Williams, Angewandte Chemie International Edition in English, 1986, 25, 487-507.

49. A. S. Borovik, Accounts of Chemical Research, 2005, 38, 54-61.

50. X. Tang, X. Luo, Q. Su, G. Wei, S.-S. Meng and A. S. C. Chan, CCS Chemistry, 2021, 3, 22452258.

51. Y. Li, Y.-T. Zhao, T. Zhou, M.-Q. Chen, Y.-P. Li, M.-Y. Huang, Z.-C. Xu, S.-F. Zhu and Q.-L. Zhou, Journal of the American Chemical Society, 2020, 142, 10557-10566.

52. J. Joy, T. Stuyver and S. Shaik, Journal of the American Chemical Society, 2020, 142, 3836-3850.

53. L. Xu, E. I. Izgorodina and M. L. Coote, Journal of the American Chemical Society, 2020, 142, 12826-12833.

54. L. Ford Courtney, J. Park Yun, M. Matson Ellen, Z. Gordon and R. Fout Alison, Science, 2016, 354, 741-743.

55. M. J. Frisch, G. W. Trucks, H. B. Schlegel, G. E. Scuseria, M. A. Robb, J. R. Cheeseman, G. Scalmani, V. Barone, G. A. Petersson, H. Nakatsuji, X. Li, M. Caricato, A. V. Marenich, J. Bloino, B. G. Janesko, R. Gomperts, B. Mennucci, H. P. Hratchian, J. V. Ortiz, A. F. Izmaylov, J. L. Sonnenberg, Williams, F. Ding, F. Lipparini, F. Egidi, J. Goings, B. Peng, A. Petrone, T. Henderson, D. Ranasinghe, V. G. Zakrzewski, J. Gao, N. Rega, G. Zheng, W. Liang, M. Hada, M. Ehara, K. Toyota, R. Fukuda, J. Hasegawa, M. Ishida, T. Nakajima, Y. Honda, O. Kitao, H. Nakai, T. Vreven, K. Throssell, J. A. Montgomery Jr., J. E. Peralta, F. Ogliaro, M. J. Bearpark, J. J. Heyd, E. N. Brothers, K. N. Kudin, V. N. Staroverov, T. A. Keith, R. Kobayashi, J. Normand, K. Raghavachari, A. P. Rendell, J. C. Burant, S. S. Iyengar, J. Tomasi, M. Cossi, J. M. Millam, M. Klene, C. Adamo, 
R. Cammi, J. W. Ochterski, R. L. Martin, K. Morokuma, O. Farkas, J. B. Foresman and D. J. Fox, Journal, 2009.

56. J.-D. Chai and M. Head-Gordon, Physical Chemistry Chemical Physics, 2008, 10, 6615-6620.

57. P. J. Hay and W. R. Wadt, The Journal of Chemical Physics, 1985, 82, 299-310.

58. W. J. Hehre, R. Ditchfield and J. A. Pople, The Journal of Chemical Physics, 1972, 56, 2257-2261.

59. P. C. Hariharan and J. A. Pople, Theoretica chimica acta, 1973, 28, 213-222.

60. M. M. Francl, W. J. Pietro, W. J. Hehre, J. S. Binkley, M. S. Gordon, D. J. DeFrees and J. A. Pople, The Journal of Chemical Physics, 1982, 77, 3654-3665.

61. D. Andrae, U. Häußermann, M. Dolg, H. Stoll and H. Preuß, Theoretica chimica acta, 1990, 77, 123-141.

62. F. Weigend and R. Ahlrichs, Physical Chemistry Chemical Physics, 2005, 7, 3297-3305.

63. A. V. Marenich, C. J. Cramer and D. G. Truhlar, The Journal of Physical Chemistry B, 2009, 113, 6378-6396.

64. I. Funes-Adoiz and R. S. Paton GoodVibes v1. 0.2; 2016. http://doi.org/10.5281/zenodo.595246.

65. S. Grimme, Chemistry - A European Journal, 2012, 18, 9955-9964.

66. Tian Lu, molclus program, Version 1.9, http://www.keinsci.com/research/molclus.html (accessed July 7, 2021) 